\title{
Demographic Consequences of Immigration
}

\author{
SVEN REINANS
}

This essay sets out to describe the opportunities furnished by Swedish population statistics for elucidating the demographic aspects of immigration, as well as presenting various figures concerning fertility, mortality and changes of marital status among the immigrant population of Sweden. The account begins with a brief presentation of the basic statistical material available in Sweden and a discussion of the term »immigrant».

\section{Statistics about immigrants in Sweden}

Swedish statistics in the field of immigration are highly detailed and voluminous by comparison with their counterparts in other countries. In principle, both population and population changes can be presented with reference to both nationality and country of birth. Children up to the age of 17 can be recorded by parental country of origin (and citizenship). Persons naturalized since 1967 can be separately accounted for. Crossreferencing of various computerized administrative registers for statistical purposes provides great opportunities of analyzing various topics of inquiry. As a matter of routine, for example, the population can be analyzed by (last) year of immigration from 1968 onwards. Full use, however, has not been made of the opportunities provided by existing registers. Thus in the published statistics of population change, country of birth has only been used in order to elucidate the fertility of foreign born mothers, and this has only been done in recent years. Immigration and emigration, deaths and changes of marital status have only been stated by citizenship. The definitions used in Swedish population statistics are governed by the rules applying to civil registration. Population statistics in Sweden refer solely to persons registered with parochial civil registration authorities. Since it is only persons intending to remain in Sweden for at least one year who can be registered in this way, it is possible for many people to reside in Sweden and also to work here without becoming simmigrants». On the other hand, the registered "immigrants» include persons not intending to settle in Sweden but residing here only for a brief, pre-determined period, e.g. visiting students and certain businessmen.

Thus Swedish statistics about immigrants are taken from the same sources as other population statistics, and all figures concerning persons born abroad or foreign nationals are directly comparable with the corresponding figures for Swedish citizens for the population as a whole. The statistics are also complete in the sense of including all persons with certain given characteristics. "Immigrants" are also, for example, taken to include children adopted from abroad, persons marrying Swedes or Nordic citizens who can settle in Sweden without having to obtain special permits. Turning to the statistics of other European countries, one finds that quite a few of them fail to include all these categories. For example, there are cases of the next of kin of EEC citizens being omitted from immigration statistics; French naturalization statistics do not include women acquiring French nationality through marriage, and so on.

The very pictures of a certain course of events conveyed by statistics in different countries are due not only to the completeness or incompleteness of the accounts but also very much to the definitions employed. 
Although the Danish and Swedish statistical systems are constructed on essentially similar principles, re-emigration statistics, for example, are not directly comparable between the two countries, because Denmark and Sweden use different periods of residence as a criterion of immigrant registration. There are extensive differences of this kind between the statistics of different countries.

Many of the differences to be found in statistical data concerning immigrants in various countries can presumably be put down to varying definitions and different degrees of coverage. The causal relationships and »mechanisms» underlying the statistics are presumably more similar as between the various countries than statistical reports would suggest. This being so, the Swedish statistical system, with the great opportunities it provides for detailed analysis of various topics, could also be very interesting as a means of shedding light on developments in other countries.

\section{"Immigrants» in Sweden}

Using the figures available in Swedish population statistics concerning foreign nationals, persons born abroad and children of persons born abroad, one can graphically illustrate the simmigrant population» of Sweden as has been done in Figure 1 . The whole area of this figure represents roughly one million people. Of these, about 400,000 are foreign nationals, roughly 330,000 were born abroad but are Swedish citizens, and about 280,000 were born in Sweden to immigrant parents. Approximately 90,000 of the people born in Sweden are foreign nationals and are included in the figure for aliens. The number of »immigrants» will vary according to which of these categories one wishes to include, and the same goes for age structure and the balance of the sexes. Persons born abroad include few children but a good deal more senior citizens than "foreign nationals». As yet, the second generation, i.e. children born in Sweden to immigrants, is very small beyond age 30 (exact figures are lacking, and the number indicated in Figure 1 is hypothetical), but they are overwhelmingly predominant among children.

The picture one obtains of demographic events in this group will also vary according to the category referred to. One popular way of indicating the demographic importance of immigrants is by saying that foreign nationals account for the whole of Sweden's natural population growth; births among foreign nationals greatly outnumber deaths, whereas the opposite applies to Swedish citizens. But in saying this one overlooks the fact that many immigrants are foreign nationals in their fertile years, whereas the majority of them have acquired Swedish nationality when reaching the ages at which mortality rises.

The Swedish way of statistically presenting immigrants is excellent for purposes of demographic analysis. On the other hand, the figures are liable to be misleading if one is interested in the cultural or social consequences of immigration. It has become a commonplace in Sweden to refer to the entire group of people included in Figure 1, i.e. including children born in Sweden, as wimmigrants». But a very large proportion of these children (more than half of them) have partly Swedish parentage, and so it should be more plausible to count them as "Swedes" than wimmigrants». It is also quite common for persons who were born abroad and have settled in Sweden to regard themselves as Swedish and to become indignant over being lumped together with »immigrants». Sweden does not have any statistics based on mother tongue, ethnic identity, etc. Nor do Swedish statistics make it possible to pinpoint "migrant workers», a term frequently occurring in international literature about immigrants. It is clear that not all the simmigrants» as shown in Figure 1 would qualify as immigrants» if the definition employed were based on their cultural situation, and only a small proportion can be regarded as mmigrant workers». 
F i g u r e 1. The population of immigrants in Sweden by sex, age and nationality at the end of 1983 .

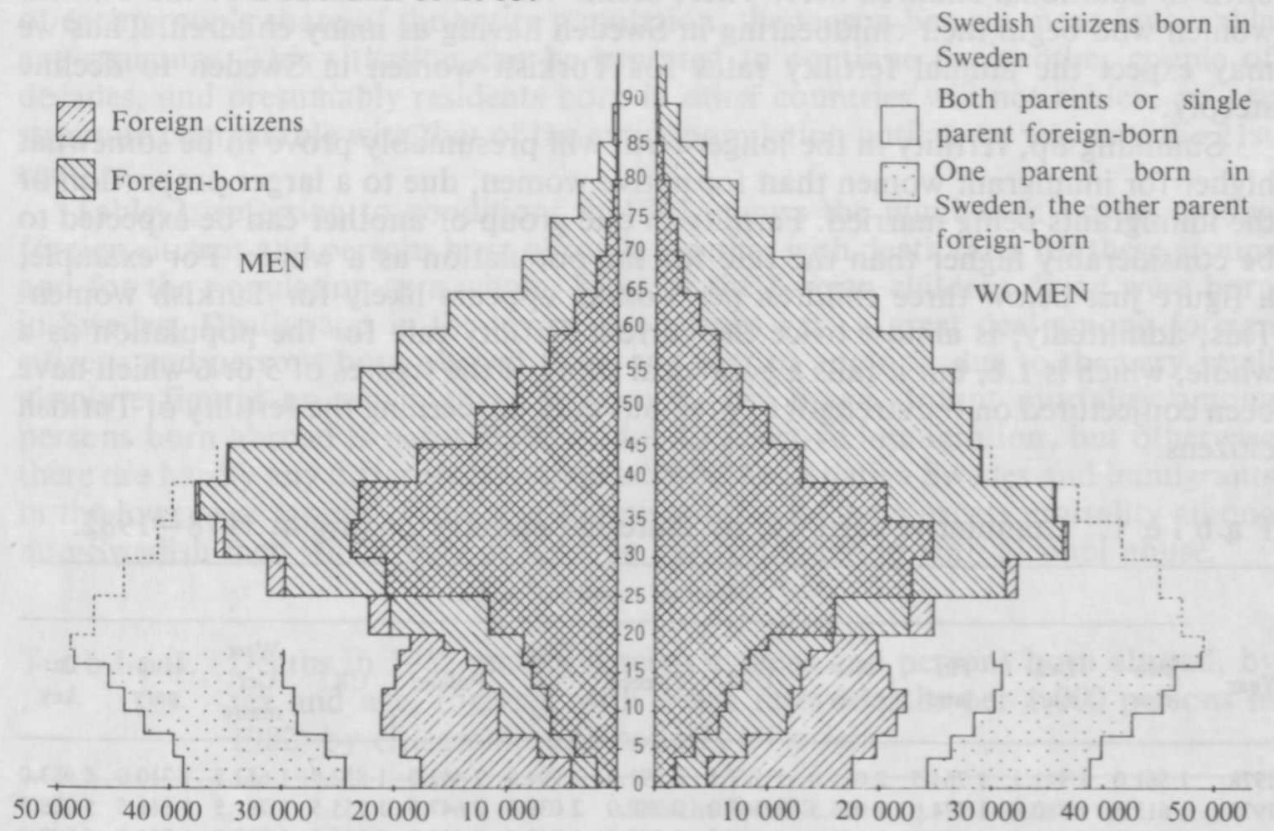

\section{Fertility}

Age-specific fertility rates for foreign citizens have been published since the beginning of the 1970s. These figures have aroused attention due to the very high level of fertility among foreign women by comparison with Swedish women. These very high figures, however, have declined considerably in recent years. Table 1 shows figures concerning cumulative fertility by country of birth. Between 1978 and 1982 , the annual fertility of women born in most foreign countries was slightly above the corresponding figure for women born in Sweden. Women born in Turkey and Poland have fertility rates well above the average.

Since immigration is often connected with marriage (or cohabitation) and, accordingly, with childbirth, it is questionable whether fertility rates of this kind, based on birth during one year, convey an accurate picture of fertility in groups which are fairly small and fluctuate heavily under the influence of immigration and emigration, as is the case with immigrant women in Sweden. These difficulties can be illustrated by means of Table 2, which is based on data concerning the position of the child among all live children borne by the mother. If cumulative fertility can be defined as the number of children which a thousand mothers, at the current fertility rate, can be expected to produce during their lifetime, the figures in Table 2 can be said to constitute (according to current fertility) the number of women per thousand who will have at least one, two etc. children in their lifetime. Several values in the table are illogical. The fact of the number of firstborn children of Turks and Poles exceeding 1,000 merely indicates, of course, an abnormal accumulation of births during the year and cannot be taken as a yardstick of fertility over a longer period. (For several years there has been heavy immigration of Turkish and Polish women as a result of marriage).

The fact of Greek women giving birth to more second children than first children in 1982 is probably also connected with fluctuations in immigration over the years. The immigration rate is low at present, but a large number of Greek women - who have now "reached" the second child - arrived in Sweden several years ago. The very high figures for Turkish women producing more than three children are due 
to women who arrived in Sweden with their families during the 1970s having given birth to additional children here. There seems very little likelihood of the Turkish women who begin their childbearing in Sweden having as many children. Thus we may expect the annual fertility rates for Turkish women in Sweden to decline steeply.

Summing up, fertility in the longer term will presumably prove to be somewhat higher for immigrant women than for native women, due to a larger proportion of the immigrants being married. Fertility in one group or another can be expected to be considerably higher than the rate for the population as a whole. For example, a figure just below three children per woman appears likely for Turkish women. This, admittedly, is almost twice the current fertility rate for the population as a whole, which is 1.6, but it falls a good deal short of the figures of 5 or 6 which have been conjectured on the strength of previous data concerning the fertility of Turkish citizens.

T a b l e 1. Cumulative fertility, by maternal country of origin, 1978-1982.

\begin{tabular}{|c|c|c|c|c|c|c|c|c|c|c|c|c|}
\hline \multirow[b]{2}{*}{ Year } & \multicolumn{12}{|c|}{ Maternal country of origin } \\
\hline & $\begin{array}{l}\text { Swe- } \\
\text { den }\end{array}$ & $\begin{array}{l}\text { Den- } \\
\text { mark }\end{array}$ & $\begin{array}{l}\text { Fin- } \\
\text { land }\end{array}$ & $\begin{array}{l}\text { Nor- } \\
\text { way }\end{array}$ & USA & Greece & $\begin{array}{c}\text { Yugo- } \\
\text { sla- } \\
\text { via }\end{array}$ & Poland & UK & $\begin{array}{l}\text { West } \\
\text { Ger- } \\
\text { many }\end{array}$ & $\begin{array}{l}\text { Hun- } \\
\text { gary }\end{array}$ & $\begin{array}{l}\text { Tur- } \\
\text { key }\end{array}$ \\
\hline 1978 & 1561.0 & 1941.5 & 1764.5 & 2005.0 & 1527.5 & 2591.0 & 1994.0 & 2442.0 & 1852.5 & 1653.5 & 1710.0 & 4953.0 \\
\hline 1979 & 1615.5 & 1880.0 & 1774.0 & 2056.5 & 1368.0 & 2282.0 & 2039.0 & 2647.0 & 1755.5 & 1781.5 & 1511.5 & 5228.5 \\
\hline 1980 & 1640.0 & 2050.5 & 1908.0 & 2201.5 & 1578.5 & 2558.0 & 1942.5 & 2447.0 & 2283.5 & 1913.5 & 1731.0 & 4898.0 \\
\hline 1981 & 1597.5 & 1862.5 & 1778.5 & 1765.5 & 1853.5 & 1997.5 & 1718.0 & 2310.0 & 1987.0 & 1743.5 & 2037.0 & 4643.5 \\
\hline 1982 & 1582.0 & 1888.0 & 1704.0 & 1794.0 & 1795.5 & 2058.5 & 1683.0 & 2176.0 & 1979.0 & 1788.5 & 1619.5 & 3932.5 \\
\hline
\end{tabular}

$\mathrm{T}$ a b 1 e 2 . Cumulative fertility, in 1982 by maternal country of origin, ${ }^{1}$ showing the proportion of cumulative fertility due to the first, second etc. child.

\begin{tabular}{|c|c|c|c|c|c|c|c|c|c|}
\hline \multirow{2}{*}{$\begin{array}{l}\text { Country of } \\
\text { birth }\end{array}$} & \multirow{2}{*}{$\begin{array}{c}\text { Cumulative } \\
\text { fertility }\end{array}$} & \multicolumn{8}{|c|}{ Portion of same derived from child No. } \\
\hline & & 1 & 2 & 3 & 4 & 5 & 6 & 7 & 8 \\
\hline $\begin{array}{l}\text { All subjects } \\
\text { born in }\end{array}$ & 1616.6 & 676.0 & 600.5 & 253.1 & 63.2 & 16.0 & 4.8 & 2.0 & 1.0 \\
\hline Turkey & 3821.0 & 1115.6 & 890.8 & 658.2 & 308.4 & 371.7 & 220.2 & 175.2 & 80.8 \\
\hline Greece & 2055.0 & 822.9 & 844.3 & 313.6 & 58.1 & 16.2 & - & - & - \\
\hline Poland & 1968.9 & 1110.0 & 691.2 & 134.4 & 36.4 & - & - & - & - \\
\hline Denmark & 1887.6 & 823.7 & 602.9 & 320.4 & 93.2 & 29.8 & 15.0 & 2.6 & - \\
\hline Norway & 1779.7 & 734.3 & 642.1 & 241.5 & 115.6 & 26.8 & 16.1 & - & - \\
\hline Finland & 1726.6 & 774.5 & 593.2 & 249.8 & 73.8 & 22.5 & 9.6 & 1.9 & 1.3 \\
\hline Yugoslavia & 1702.5 & 795.7 & 650.3 & 211.4 & 38.4 & 3.3 & 1.7 & 1.7 & - \\
\hline
\end{tabular}

1 Fertility is computed according to the mother's year of birth instead of her age and using population at year's end as the base instead of average population. Consequently the total cumulative fertility deviates somewhat from the figures in Table 1. The great difference for women born in Poland is due to the heavy Polish immigration occurring in 1982.

\section{Mortality}

The published population statistics include data concerning deaths by citizenship. Immigrant mortality has not yet been made a subject of any more comprehensive surveys in Sweden. 
Only 1.5 percent of all persons dying in Sweden in 1982 were foreign citizens, while 4.7 percent had been born abroad. Both these figures are a good deal short of each group's share of the entire population, the reason being a more favourable age structure. This situation can be expected to continue for another couple of decades, and presumably residents born in other countries will not achieve an age structure comparable with that of the entire population until some way into the 21 st century.

Table 3, referring to conditions in 1982, shows the number of deaths among foreign citizens and persons born abroad, together with death rates for these groups and for the population as a whole. Most of the foreign children dying were born in Sweden. Death rates in the lowest age groups vary a great deal among foreign citizens and persons born abroad from one year to another, due to the very small absolute figures on which these frequencies are based. Infant mortality among persons born abroad is naturally low, due to selective immigration, but otherwise there are hardly any differences in mortality between native Swedes and immigrants in the lower age groups. From age 20 onwards, there is an excess mortality among non-Swedish men which may at least be partly connected with alcohol abuse.

T a b l e 3. Deaths in 1982 among foreign citizens and persons born abroad, by sex and age, together with death rates (deaths per 1,000 persons in 1982) by citizenship and country of origin.

\begin{tabular}{|c|c|c|c|c|c|c|c|c|c|c|c|c|}
\hline \multirow[t]{2}{*}{ Age } & \multicolumn{3}{|c|}{ Aliens } & \multicolumn{7}{|c|}{ Deaths in 1982} & \multicolumn{2}{|c|}{ Born abroad } \\
\hline & Men & Women & $\begin{array}{l}\text { Both } \\
\text { sexes }\end{array}$ & Men & Women & $\begin{array}{l}\text { Both } \\
\text { sexes }\end{array}$ & Men & Women & Men & Women & Men & Women \\
\hline 0 & 23 & 30 & 53 & - & - & - & 7.14 & 6.53 & 7.14 & 9.58 & - & - \\
\hline $1-4$ & 8 & 7 & 15 & 1 & 1 & 2 & 0.37 & 0.29 & 0.57 & 0.53 & 0.21 & 0.18 \\
\hline $5-9$ & 2 & 6 & 8 & 1 & 1 & 2 & 0.19 & 0.15 & 0.11 & 0.35 & 0.10 & 0.09 \\
\hline $10-14$ & 6 & 3 & 9 & 2 & 2 & 4 & 0.14 & 0.14 & 0.34 & 0.17 & 0.18 & 0.16 \\
\hline $15-19$ & 9 & 5 & 14 & 10 & 6 & 16 & 0.59 & 0.27 & 0.65 & 0.34 & 0.68 & 0.40 \\
\hline $20-24$ & 14 & 12 & 26 & 18 & 12 & 30 & 0.83 & 0.34 & 0.89 & 0.60 & 0.83 & 0.50 \\
\hline $25-29$ & 33 & 9 & 42 & 46 & 15 & 61 & 1.09 & 0.43 & 1.35 & 0.35 & 1.46 & 0.46 \\
\hline $30-34$ & 53 & 18 & 71 & 68 & 23 & 91 & 1.22 & 0.58 & 1.98 & 0.69 & 1.81 & 0.61 \\
\hline $35-39$ & 66 & 12 & 78 & 97 & 32 & 129 & 1.75 & 0.91 & 2.89 & 0.64 & 2.66 & 0.99 \\
\hline $40-44$ & 60 & 15 & 75 & 106 & 46 & 152 & 2.45 & 1.33 & 3.40 & 1.17 & 3.11 & 1.58 \\
\hline $45-49$ & 73 & 21 & 94 & 143 & 76 & 219 & 4.02 & 2.19 & 6.05 & 2.20 & 5.39 & 2.79 \\
\hline $50-54$ & 93 & 33 & 126 & 197 & 98 & 295 & 6.26 & 3.42 & 10.45 & 4.38 & 8.73 & 3.68 \\
\hline $55-59$ & 95 & 29 & 124 & 249 & 102 & 351 & 10.52 & 5.40 & 16.19 & 5.56 & 13.06 & 4.32 \\
\hline $60-64$ & 77 & 36 & 113 & 249 & 160 & 409 & 17.00 & 8.08 & 21.91 & 10.49 & 18.56 & 9.21 \\
\hline $65-69$ & 74 & 36 & 110 & 252 & 184 & 436 & 27.82 & 13.79 & 39.61 & 15.57 & 30.62 & 14.72 \\
\hline $70-74$ & 67 & 44 & 111 & 283 & 250 & 533 & 44.97 & 23.72 & 60.14 & 25.00 & 50.83 & 26.35 \\
\hline $75-79$ & 47 & 46 & 93 & 248 & 275 & 523 & 73.78 & 42.86 & 78.33 & 41.89 & 73.99 & 42.19 \\
\hline $80-84$ & 31 & 43 & 74 & 190 & 317 & 507 & 119.92 & 78.35 & 107.64 & 70.84 & 118.79 & 77.25 \\
\hline $85-89$ & 18 & 24 & 42 & 96 & 228 & 324 & 182.20 & 136.95 & 150.00 & 101.69 & 159.47 & 122.75 \\
\hline $90-$ & 13 & 29 & 42 & 48 & 160 & 208 & 298.61 & 240.33 & 250.00 & 263.64 & 252.63 & 219.18 \\
\hline All ages & 862 & 458 & 1320 & 2300 & 1991 & 4291 & & & & & & \\
\hline
\end{tabular}

\section{Changes of marital status}

Changes of marital status in immigrant groups are difficult to analyze, since the population is constantly changing as a result of immigration and emigration and because immigrants can also marry (and divorce) persons domiciled abroad. In cases 
of this kind, there are no data concerning the spouse. Immigration can take place before or after marriage, or an immigrant marrying somebody domiciled abroad may leave Sweden. Similarly, immigration may be connected with a divorce, and whether or not a divorce gets into the statistics will depend on whether immigration is registered before or after the formal dissolution of the marriage. Four percent of all men who married in 1982 were married to women domiciled outside Sweden, the corresponding figure for women being 3.4 percent. Three percent of divorced men had exwives domiciled abroad, the corresponding figure for women being 4.5 percent.

Confining ourselves to cases where both spouses were domiciled in Sweden at the time of their marriage or divorce, we obtained for 1982 the rates shown in Table 4. This table shows the proportion of all marriages and divorces respectively in which one or both spouses were foreign citizens or natives of other countries. As can be seen from the table, both sexes tend to marry a native Swede rather than another immigrant, but divorces are slightly more common between immigrants. The fact of at least one spouse in 25 percent of the divorces but only in 16 percent of the marriages having been born abroad suggests a very high divorce rate among immigrants, but these figures cannot be directly related to one another. It is evident from other data that there are very great differences between immigrant communities where divorce is concerned. For example, divorce appears to be very uncommon among Greek and Turkish women while immigrants from Latin America and certain Asian and African countries have high divorce rates.

$\mathrm{T}$ a b l e 4. Percentage of marriages and divorces in 1982 in which at least one or both parties were foreign citizens or natives of other countries.

\begin{tabular}{lcccc}
\hline & \multicolumn{4}{c}{ Percentages either foreign citizens or born abroad } \\
\cline { 2 - 5 } & Both & Husband only & Wife only & At least one \\
\hline $\begin{array}{l}\text { Newly married, } \\
\text { by citizenship }\end{array}$ & 3.1 & 3.2 & 4.3 & 10.6 \\
by country of birth & 4.7 & 5.2 & 6.1 & 16.0 \\
$\begin{array}{l}\text { Newly divorced, } \\
\text { by citizenship }\end{array}$ & 5.1 & 5.2 & & \\
by country of birth & 9.4 & 8.2 & 7.5 & 14.9 \\
\hline
\end{tabular}

